\title{
AN EVALUATION OF POST-OCCUPANCY OF SUSTAINABLE HOUSING
}

\author{
SHAMIL NAOUM ${ }^{1}$, KAREN BUCKLEY ${ }^{2}$ and DANIEL FONG ${ }^{3}$ \\ Department of the Built Environment, London South Bank University, \\ 103 Borough Road, London, United Kingdom. \\ ${ }^{l}$ E-mail: naoums@lsbu.ac.uk \\ ${ }^{3}$ E-mail: fongd@lsbu.ac.uk
}

\begin{abstract}
This paper is based on an MSc dissertation by Buckley (2011) who explored the current state of post-occupancy evaluation in relation to the residential construction sector. The aim was to develop a conceptual framework for the development of post-occupancy evaluation as a sustainability benchmarking tool. In-depth exploratory interviews were carried out with five project managers with affordable housing development expertise. Three major themes emerged from the template analysis used to code and categorise the data: design and construction, postcompletion practices, and post-occupancy evaluation. The interviews indicated that the process of knowledge transfer to new occupants is a critical factor which deserves future post-occupancy evaluation. Other key issues were consumption monitoring, handling the discrepancies between the performance of buildings as-designed and as-used and the extent to which knowledge should be shared more widely in the sector.
\end{abstract}

Keywords: Post-occupancy evaluation, sustainable homes, affordable housing.

\section{Introduction}

UK government policy in 2006 set the target of achieving zero net carbon emissions from energy use in new homes by 2016, to be achieved through a complementary relationship between the planning system, building regulations and the Code for Sustainable Homes (CSH) design code (DCLG, 2007). The success of the Code for Sustainable Homes (DCLG, 2006) (hereafter referred to as 'the code') is therefore of fundamental importance if the UK is to achieve target cuts in carbon emissions.

Whilst the code contains performance targets for newbuild dwellings, the design and construction methods to meet them are not prescribed. A number of case studies reviewed consider the implementation of innovative design and construction strategies and technologies in place of more traditional approaches to meet the code's requirements. However, currently there is limited opportunity within the procurement process to analyse how well buildings perform postoccupation and therefore limited understanding of the relationship between predicted design and how buildings function in reality; the interrelationship between the occupant, the building and consumption; and occupants' satisfaction with their new homes.

Data from Carbon Buzz information sharing project suggests that design stage predictions often underestimate actual energy consumption and carbon emissions and the 
Royal Academy of Engineering (2010) highlighted the need for reliable actual performance data from new buildings, suggesting that all new publicly procured buildings "must include post-occupancy commissioning and a full post occupancy evaluation of performance with publication of the results to a national database".

There is no universally accepted postoccupancy evaluation (POE) definition or method. The US Federal Facilities Council describes POE as a process of "systematically evaluating the performance of buildings after they have been built and occupied for some time" (Federal Facilities Council et al, 2002). Cooper (2001) noted a re-emerging research agenda for POE in the UK following the Egan Report's call for the construction industry to focus on the customer. This includes a significant role for POE as a benchmarking aid for sustainable construction.

The statistical data for the code reported that $89 \%$ of the 18,339 post-construction stage certificates awarded had been built for the public sector (DCLG, 2011). This suggests that registered providers of affordable housing are leading the way in the development of design and construction strategies to meet the code's requirements, for this reason the study focuses on the affordable housing segment of the residential construction sector.

\section{Aim and methodology of the research}

This research seeked to explore the current state of POE in relation to the residential construction sector and to develop a conceptual framework for the development of POE as a sustainability benchmarking tool.

Structured interviews with five affordable housing experts were carried out to gain insights into their experiences of delivering and managing housing, meeting sustainable design requirements, and to explore opportunities within existing real-life practice for the assessment of residential buildings post-construction. Each interview was transcribed for analysis. An initial coding template was developed based on the key themes outlined in the interview guide. The template was reviewed and amended after each interview. Changes to the code and category definitions were reviewed against previously analysed interviews.

The interview transcripts were unitised according to the codes and categories final code template. Variable-oriented and caseoriented analysis was used to develop tables, matrices and networks to display the data, identify relationships and draw conclusions.

\section{Results}

All organizations surveyed carried out some form of POE activity. The evaluation included some form of occupant satisfaction survey and property inspections at the end of the defects liability period. The POE activities took the forms of written surveys and questionnaires; telephone surveys; reported defects trend monitoring; informal feedback through settling in checks; and end of defects liability period (DLP) inspections.

\subsection{Occupant surveys}

Occupant satisfaction surveying was not necessarily linked in with the end of defects liability period inspections. Table 1 illustrates different respondents' approaches to the timing of occupant satisfaction survey.

Table 1. When do respondents carry out occupant satisfaction surveys?

\begin{tabular}{|c|c|c|c|c|}
\hline $\begin{array}{l}\text { Resp- } \\
\text { onden }\end{array}$ & $\begin{array}{c}\text { Shortly } \\
\text { after } \\
\text { occupation }\end{array}$ & $\begin{array}{c}\text { Mid- } \\
\text { way } \\
\text { through } \\
\text { DLP }\end{array}$ & $\begin{array}{l}\text { Before end } \\
\text { of DLP } \\
\text { inspections }\end{array}$ & $\begin{array}{c}\text { After } \\
\text { end of } \\
\text { DLP }\end{array}$ \\
\hline $\mathrm{A}$ & & $\mathrm{T}$ & & \\
\hline B & & & & W \\
\hline C & & $\mathrm{T}$ & & \\
\hline D & & W & & \\
\hline $\mathrm{E}$ & $\mathrm{W}$ & & $\mathrm{W}$ & \\
\hline
\end{tabular}

$\mathrm{W}=$ Written survey $\mathrm{T}=$ Telephone survey 
Table 2 summarises the respondents' attitudes towards consumption monitoring of newbuild properties. Respondent A was keen to investigate user's behaviour as part of consumption monitoring studies and was particularly interested in whether increased technical efficiencies led to people using more energy because the home had become cheaper to run (a phenomena known as the Jevons Paradox). Respondent D had firsthand experience of paradox through involvement in an energy monitoring study: some energy conscious occupants had managed to reduce their electricity bills whereas the perception of cheaper utility bills encouraged others to increase electrical consumption.

Table 2. Positive and negative views \& opinions on consumption monitoring

\begin{tabular}{|c|c|c|}
\hline $\begin{array}{l}\text { Resp- } \\
\text { ondent }\end{array}$ & $\begin{array}{l}\text { Consumption } \\
\text { Monitoring (+) }\end{array}$ & $\begin{array}{l}\text { Consumption } \\
\text { Monitoring (-) }\end{array}$ \\
\hline $\mathrm{A}$ & $\begin{array}{l}\text { Investigate impact of } \\
\text { energy efficiency on } \\
\text { occupant behaviour } \\
\text { (Jevons paradox). } \\
\text { Smart metering used } \\
\text { for solar PV; would be } \\
\text { good to extend use. }\end{array}$ & $\begin{array}{l}\text { Smart } \\
\text { monitoring costs } \\
\text { not incentivised } \\
\text { where there is } \\
\text { no feed-in tariff } \\
\text { incentive. }\end{array}$ \\
\hline B & $\begin{array}{l}\text { Consumption is heavily } \\
\text { underlined in the code, } \\
\text { would be useful to find } \\
\text { out if the measures } \\
\text { were working. }\end{array}$ & \\
\hline $\mathrm{C}$ & $\begin{array}{l}\text { Useful for the } \\
\text { organisation to have } \\
\text { feedback. }\end{array}$ & $\begin{array}{l}\text { Concerns with } \\
\text { imposition onto } \\
\text { occupants lives. }\end{array}$ \\
\hline D & $\begin{array}{l}\text { Data logging providing } \\
\text { useful information. } \\
\text { Better information } \\
\text { available for assessing } \\
\text { manufacturers' claims. }\end{array}$ & $\begin{array}{l}\text { Data logging } \\
\text { costly on a large } \\
\text { scale basis. }\end{array}$ \\
\hline $\mathrm{E}$ & $\begin{array}{l}\text { Informal monitoring on } \\
\text { a showcase scheme. }\end{array}$ & \\
\hline
\end{tabular}

Three respondents had experience of working with universities and other external agencies to monitor the effectiveness of new technologies (solar panels for D and E). D was involved in a field trial where data collectors were installed to transmit information about data usage to a university to monitor - regarding this as a good idea (information would be useful to validate the marketing claims made by manufacturers). The main barrier to the wider implication of this technology was cost.

\subsection{The value of POE - lesson learning}

All respondents reported lesson learning from previous instances of renewable technology installation. Feedback from customers and the project team was also brought together by respondents and shared with colleagues through a number of fora (project groups, development committees, boards) and in some instances fed through to design briefs. The approach to information sharing ranged from ad hoc to highly structured.

The preferred code strategy for respondents $\mathrm{A}$ and $\mathrm{C}$ had been informed by previous experiences, with bad experiences causing certain technologies to be avoided where possible. Information was shared with certain key personnel within the organisation however this was done ad hoc ran rather than through a formal process.

Respondent E also referred to lesson learning occurring on an ad hoc basis, however this was within the more formal confines of a client consultation project group, e.g. the identification of conflicts caused through adherence to multiple design codes.

Respondents B and D completed learning exercises with the project team for each development and then reported back to internal project groups to be incorporated into future developments by amending the design brief as necessary. Lesson learning also took place on a more regular basis through regular design review meetings. 


\subsection{The value of POE - knowledge sharing}

Knowledge sharing practices varied amongst the respondents. Respondent $\mathrm{C}$ had identified gaps in the knowledge-sharing process between different offices in their group and hindered further by a lack of homogeneity in working practices at different locations. Information about available knowledge was elusive, even when specifically sought after. The respondent's organisation was considering two options to address this problem: 1) A project office to hold and maintain information; 2) Post-project review reports returning to the original development approval panel.

Respondent E's organisation was working with external agencies (universities and the Building Research Establishment) to gain insights into solar photovoltaic technology which they viewed as an important part of the knowledge sharing process. Information about the project was shared through a bimonthly working group. The development team at E's organisation was small and located within the same office. Close proximity meant that information could easily be spread 'unofficially' i.e. tacitly, which E viewed as an advantage.

Attitudes towards knowledge sharing beyond own organisation varied. Whilst most respondents acknowledge the benefits of sharing knowledge industry-wide, respondent $\mathrm{D}$ did not participate in any existing fora as they regarded the knowledge their department held as superior to much of the information available elsewhere and therefore a "hard-won and valuable resource".

\subsection{Standardised assessments}

All of the respondents were asked whether there would be any value in the creation of a standardised assessment for all properties certified under CSH. Four respondents thought some form of standardised assessment would be useful and suggested that such an assessment could be used to obtain information about:
- Actual fuel costs

- Information about ease of use

- Impact on property 'live-ability'

- Occupant attitudes towards the property and installed technology

- Occupant satisfaction

Views varied as to who would be best placed to carry out this sort of survey. D left the responsibility to the code assessor, whereas B though each individual organisation should survey its own occupants.

Respondents identified the following potential positive outcomes of standardised assessments:

- Could be used as a learning opportunity for occupants as well as professionals.

- Would allow consideration to be given to the influence of occupant behaviour on property performance.

- Would help prevent the code from becoming a box-ticking exercise.

The opportunity for sector-wide information sharing through standardised assessment was seen by most as positive outcome; Respondent A considered knowledge to be a valuable resource and was concerned about sharing information and knowledge too widely. Conversely Respondent B felt that the sector should share information more but that this was hindered by "the competitive nature of the industry".

\section{Proposed Network for Post-occupancy Evaluation}

Following the analysis of the data unitised to the POE code and categories the following adjustments were made to the network; additional nodes were added to show the key learning and evaluation activities: building inspection and monitoring, learning from occupant surveys and intra-sector information sharing (figure 1). 


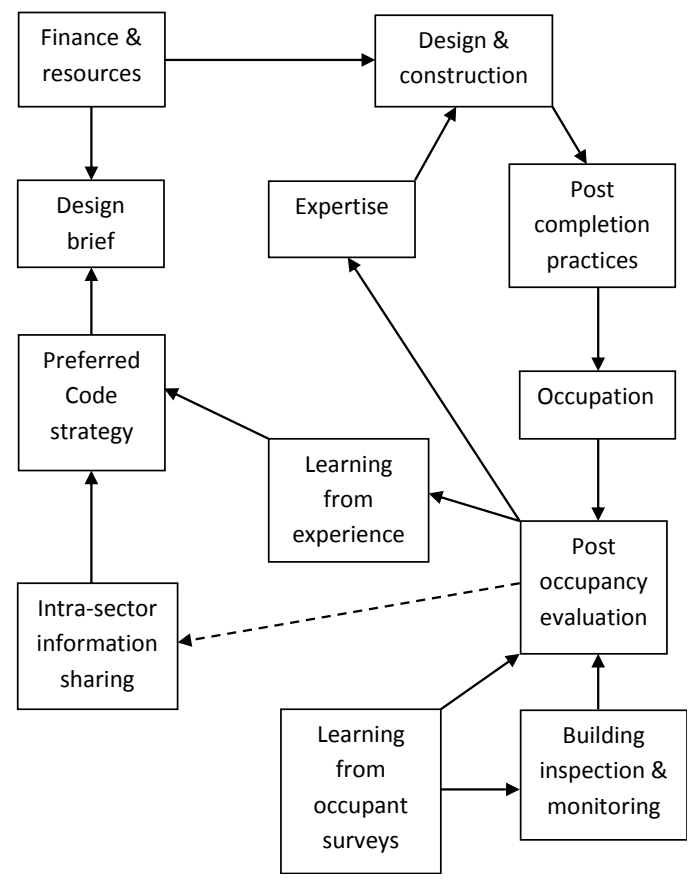

Figure 1. Network post-analysis of POE code.

Figure 2 shows a developed conceptual framework for the future development of POE as a benchmarking aid for sustainable residential development.

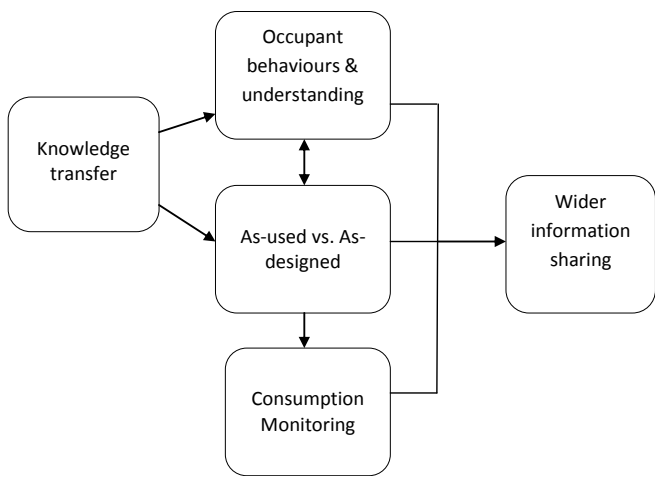

Figure 2. Theoretical framework for the future development of POE as a benchmarking aid for sustainable residential development.
The framework depicted in figure 2 represents five main areas highlighted from the research. The themes of knowledge transfer and occupant behaviours and understanding require further examination for fuller understanding of building performance in the domestic context. The tension between the performance of buildings as-used vs. as designed has been picked up briefly in the literature but needs further exploration to improve understanding in the context of sustainable home performance. Ultimately consideration should be given to the optimum data required for useful information sharing amongst the wider sector.

\section{Conclusions}

The literature review demonstrated that international level policy had been filtered down to the residential construction sector through carbon and energy use reduction commitments for the sector. The findings confirmed that although $\mathrm{CSH}$ has been developed as a voluntary mechanism for improving standards, in reality affordable housing professionals have extensive experience of developing homes to the code due to public subsidy arrangement, but also to advance expertise through participation in trials and showcase schemes.

The research found that all of the respondents had developed preferred strategies to implement the code - none of which were identical. The fabric first approach recommended in the literature was common, with additional technology choices based on financial considerations (subsidy) and user-feedback. Respondents were more likely to choose technology that supplemented rather than replaced more conventional ones.

One theme that emerged was respondents' concerns to minimise the impact of technologies on occupants, preferring 
strategies that did not require occupant interaction or were not the sole source of heating and hot water. In common with the literature review, a wide range of sustainable technologies were cited in the interviews however whilst the majority of the literature focuses heavily on the technical and financial aspects of delivering zero carbon homes, respondents were focused on balancing these with a need to deliver code solutions that were as simple and user-friendly as possible.

A number of factors were identified that in the literature that distinguish domestic and non-domestic buildings. The consideration of the history of POE in the UK highlights that the evaluation have most recently been championed by the facilities management field. The individual home presents a diametric contrast to the professionally managed environment of the commercial building. The occupant-manager may have the necessary knowledge, understanding or ability to manage the systems in their home. The majority of respondents felt that a standardised POE would provide useful information but were cautious about drawing comparisons between different households and sites from generic assessment.

Respondents raised similar concerns to those explored in the literature, in relation to funding and liability. Whilst happy to carry out POE to meet the business needs of their own organisations, respondents were concerned about the consequences of assessing schemes against their sustainability rating. The role of occupants was considered to be as important as the sustainability strategy on the as-built building performance.

Knowledge transfer was prominent theme in the interviews, with emphasis placed on the handover of knowledge and documentation from respondents to other colleagues, then by other colleagues to occupants. Inconsistencies were seen in respondent's accounts of the use of the home user guide and the responsibilities of colleagues. This is an area of weakness not seen in the literature review, possibly due to the professional nature of commercial building management.

\section{References}

Buckley, K., Post-Occupancy Evaluation of Sustainable Housing, MSc dissertation (unpublished), London South Bank University, Depatrment of the Built Environment, London, UK, 2011.

CarbonBuzz, www.carbonbuzz.org, accessed $7^{\text {th }}$ June 2012.

Cooper, I., Post-occupancy evaluation - where are you?, Building Research \& Information, 29(2), 158-163, 2001.

Department for Communities and Local Government, Code for Sustainable Homes: A step-change in sustainable building practice, Communities and Local Government Publications, West Yorkshire, 2006.

Department for Communities and Local Government, Building a Greener Future: policy statement, Communities and Local Government Publications, West Yorkshire, 2007.

Department for Communities and Local Government, Code for sustainable homes and energy performance of buildings: cumulative and quarterly data for England, Wales and Northern Ireland up to December 2010, Crown Copyright, February, 2011.

Federal Facilities Council, Board on Infrastructure and the Constructed Environment, National Research Council Learning from our Buildings: A State-of-the-Practice Summary of PostOccupancy Evaluation, National Academy Press, 2002.

The Royal Academy of Engineering, Engineering a low carbon built environment, London, 2010. 